(C) 1984. The Genetical Society of Great Britain

\title{
DENSITY, DISPERSAL AND NEIGHBOURHOOD SIZE IN THE LAND SNAIL THEBA PISANA
}

\author{
ROBERT H. COWIE* \\ Department of Zoology, University of Liverpool, Liverpool, L69 3BX, U.K.
}

Received 18.x.83

\section{SUMMARY}

\begin{abstract}
Studies of population structure were undertaken at six sites in the Tenby (South Wales) colony of the Mediterranean coastal land snail Theba pisana (Müller). Over four years, the density of adult (two-year-old) snails was estimated as ranging from 39 to $202 \mathrm{~m}^{-2}$ during the summer active season; half-grown juvenile (one-year-old) density was estimated during the same time of year as between 13 and $436 \mathrm{~m}^{-2}$; no estimates were made of the density of younger snails. Significant aggregation was shown for both adults and juveniles. Estimates of variance of dispersal over 100 days $\left(0.489\right.$ to $\left.1.601 \mathrm{~m}^{2}\right)$ suggest that $T$. pisana is rather sedentary when compared with the few other snail species for which comparable information is available. Combining the data on density and dispersal with an estimate of variance of family size, yields estimates of effective neighbourhood size ranging from 115 to 4130 . These results are compared with data for other organisms, especially other species of land snail.
\end{abstract}

\section{INTRODUCTION}

Knowledge of population structure is essential for understanding the maintenance of genetic diversity; and the concepts of neighbourhood and effective population size (Wright, 1969) are of considerable importance in population genetics. Some confusion has arisen in the literature about the distinction between these two concepts. For a discrete, panmictic population, effective population size is the size of an idealised population equivalent genetically to the real one; and this concept is not applicable to a continuously distributed population in which neighbourhood size, combining both density and dispersal within the population, is appropriate. However, many real populations will probably be intermediate in structure between the discrete and continuous models.

This paper presents a study of density and dispersal in the coastal Mediterranean land snail Theba pisana (Müller), a helicid snail slightly smaller than Cepaea spp. The populations studied vary in area but are large enough to be considered as continuously distributed populations, rather than localised discrete units, and estimates of neighbourhood size within them may be calculated from the estimates of density and dispersal. Both density and dispersal do of course have considerable ecological interest in their own right.

The distribution of $T$. pisana extends from the Mediterranean up the Atlantic coasts of Spain, Portugal, France and Belgium, and reaches its northern limit at a small number of localities in the south-west of the British Isles (Kerney, 1976; Cowie, 1982). The largest of these British colonies is at Tenby in South Wales, and it was here that this study was carried out.

* Present address: The Galton Laboratory, Department of Genetics and Biometry, University College London, Wolfson House, 4 Stephenson Way, London NW1 2HE, U.K. 
Six sites were selected for the study (see Cowie, 1984a, for locations of these sites, and Cowie, 1982, for detailed descriptions of them).

\section{Methods}

\section{(i) Density}

At Tenby, Theba pisana is biennial, breeding in late summer and autumn of the second year. In early and mid summer there are two distinct sizeclasses in the population, viz., adults which are just about to breed, and approximately half-grown one-year-old juveniles (Cowie, 1984b). Allocating snails by eye to one of these classes is not difficult. In July 1981, thirty random quadrats $(0.25 \times 0.25 \mathrm{~m})$ were sampled within the area of about $25 \times 5 \mathrm{~m}$ which constitutes site 2 , and numbers of adults and juveniles recorded in each. Population density could then be estimated at this site. The data were also used to obtain information on the pattern of the snails' distribution, by means of the index of dispersion (Southwood, 1978):

$$
I_{D}=\frac{s^{2}(n-1)}{\bar{x}}
$$

in which $\bar{x}$ is the mean sample size, $s^{2}$ is the variance, and $n$ is the number of samples. $I_{D}$ is approximately distributed as $\chi^{2}$ with $n-1$ degrees of freedom, and departure from random dispersion can hence be tested.

\section{(ii) Dispersal}

Dispersal was measured by releasing 200 near-adults and 200 approximately half-grown juveniles, marked with a spot of paint, from a central release point at each of two sites (sites 2 and 6). Release of individually marked animals from where they were found, although theoretically preferable since it reduces unnatural dispersal due to disturbance, overcrowding at the release point, and situation of the release point in an unfavourable micro-habitat (Cowie, 1980 a), was not practicable in this study. The experimental snails were collected immediately prior to marking and release, on 9 July 1980, and dispersal distances were measured after about 100 days $(17,18$ October 1980), for snails recaptured both dead and alive. Suitable habitat within about $20 \mathrm{~m}$ of the release points was searched for marked snails.

\section{Results}

\section{(i) Density}

The quadrat data gave estimates of population density of $197 \mathrm{~m}^{-2}$ for adults and $203 \mathrm{~m}^{-2}$ for juveniles. Extrapolation from data obtained at the five other sites and in four other years (Cowie, 1982) gave estimates ranging from 39 to $202 \mathrm{~m}^{-2}$ for adults and from 13 to $436 \mathrm{~m}^{-2}$ for juveniles (tables 1 and 2-no data available for sites 2 and 6 in 1980). The values calculated for the index of dispersion ( 582 for adults, 77 for juveniles) indicate highly significant aggregation ( $p<0.001$ in both cases). An $F$-test on the values of $s^{2}$ ( 247 for adults, 34 for juveniles) suggests that the adults were more aggregated than the juveniles $(p<0.02)$. 
TABLE 1

Estimated of numbers of adult snails per $m^{2}$ during summer

\begin{tabular}{ccccccc}
\hline Year & Site 1 & Site 2 & Site 3 & Site 4 & Site 5 & Site 6 \\
\hline 1977 & 148 & 180 & 202 & 87 & 52 & 100 \\
1978 & 92 & 126 & 110 & 100 & 98 & 113 \\
1979 & 57 & 94 & 114 & 69 & 72 & 181 \\
1980 & 55 & - & 77 & 88 & 86 & $\overline{155}$ \\
1981 & 39 & 196 & 42 & 132 & 40 & 152 \\
\hline
\end{tabular}

TABLE 2

Estimates of numbers of juvenile snails per $m^{2}$ during summer

\begin{tabular}{ccccccc}
\hline Year & Site 1 & Site 2 & Site 3 & Site 4 & Site 5 & Site 6 \\
\hline 1977 & 411 & 417 & 436 & 145 & 113 & 235 \\
1978 & 292 & 153 & 279 & 401 & 318 & 387 \\
1979 & 97 & 77 & 258 & 198 & 100 & 223 \\
1980 & 126 & - & 300 & 271 & 42 & - \\
1981 & 154 & 203 & 19 & 134 & 13 & 397 \\
\hline
\end{tabular}

(ii) Dispersal

Dispersal distances are presented as histograms (fig. 1). Following Kerster (1964) and Greenwood (1976), variance of dispersal along one axis (required for the estimation of neighbourhood size) has been calculated as half the variance of dispersal in all directions (absolute or radial dispersal), which was measured, from the relation used by Cowie (1980a, after Dobzhansky and Wright, 1943):

$$
\text { Variance of absolute dispersal }=\frac{\sum r^{2} f}{n-1}
$$

in which $r$ is the median value of each $10 \mathrm{~cm}$ class in the histograms, $f$ is the number of observations in each class, and $n$ is the total recaptures. The resulting values (in $\mathrm{m}^{2}$ ) of the variance of dispersal along one axis are:

\begin{tabular}{|c|c|c|c|c|}
\hline Site 2 & $\begin{array}{l}\text { adults } \\
\text { juveniles }\end{array}$ & $\begin{array}{l}1 \cdot 601 \\
1 \cdot 580\end{array}$ & Site 6 & $\begin{array}{l}\text { adults } \\
\text { juveniles }\end{array}$ \\
\hline
\end{tabular}

They are probably over-estimates of the true variance of dispersal, for the reasons given above (methods section), although the fact that snails moving long distances from the release points are less likely to be captured than those moving less far, may offset this.

\section{(iii) Neighbourhood size}

Wright (1969) gave the neighbourhood size for a two-dimensional population as

$$
N=4 \pi \sigma^{2} d
$$

in which $N$ is the number of organisms in the neighbourhood area, $\sigma^{2}$ is the variance of dispersal along a single axis, and $d$ is the density of the breeding population. 
20

(a)

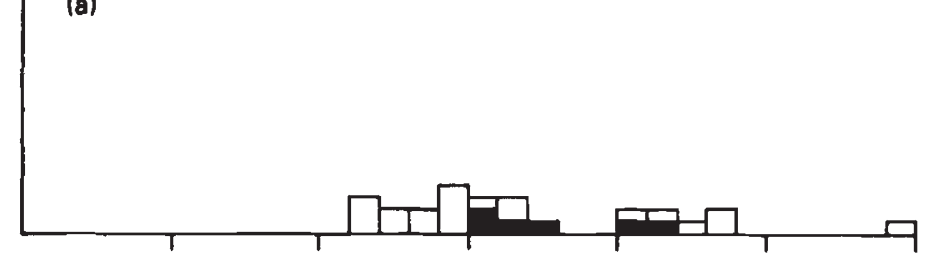

207 (b)
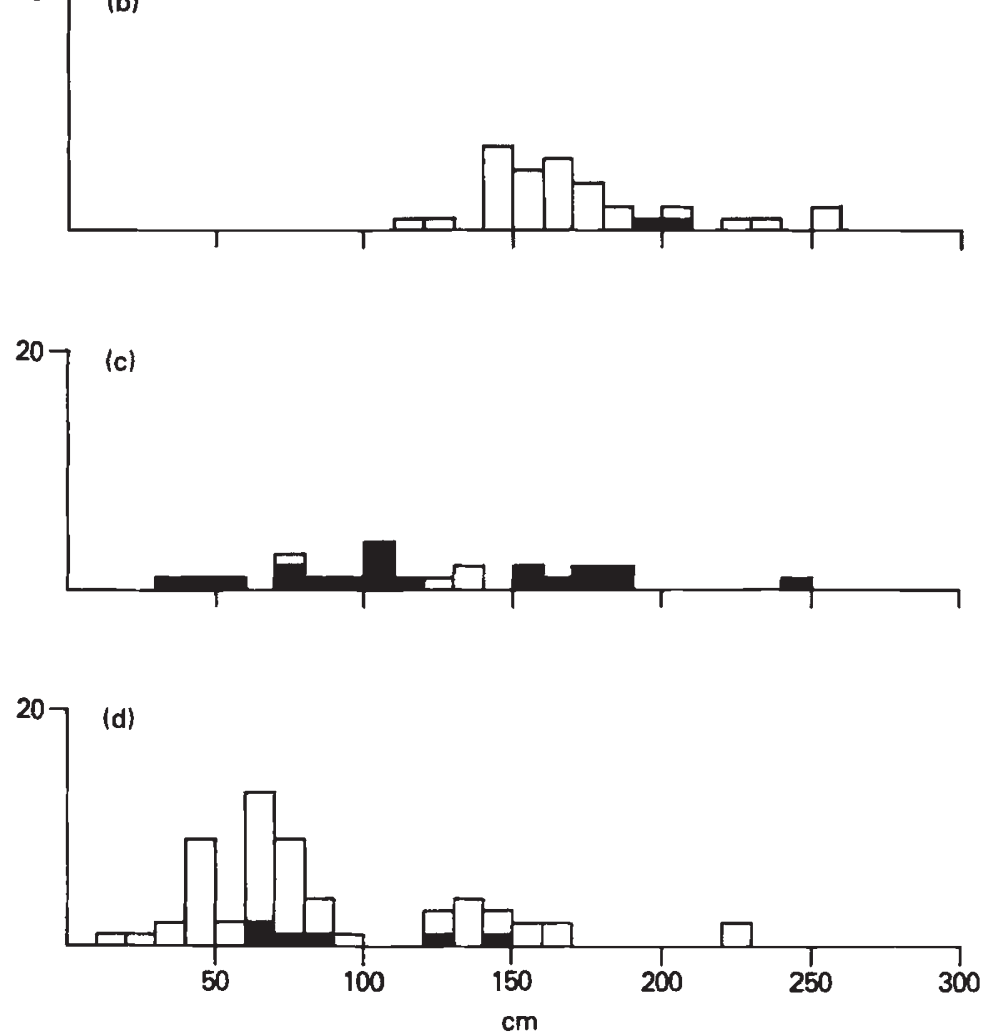

FIG. 1. Distance dispersed by snails after 100 days, grouped into $10 \mathrm{~cm}$ in tervals. Shaded areas indicate snails recaptured dead. (a) Site 2 adults (26 recaptures). (b) Site 2 juveniles (33 recaptures). (c) Site 6 adults ( 24 recaptures). (d) Site 6 juveniles ( 58 recaptures).

The variance of dispersal along a single axis for $T$. pisana at Tenby for a 100 day period during the active season was estimated above as between 0.489 and $1.601 \mathrm{~m}^{2}$. The snails are active at Tenby from about early April until late October, although some activity takes place all year round. Since they die soon after breeding, the lifetime and generation time are approximately equivalent and equal to about two years (Cowie, 1984b). Therefore, if variance of dispersal increased in proportion to elapsed time (Lamotte, 1951; Greenwood, 1974), and adult and juvenile dispersal were similar, its value per generation would be about four times that for 100 
days. Although nothing is known of dispersal of newly-hatched juveniles, the values obtained above for 100 days are probably over-estimates, and it seems reasonable to take these as the minimum estimates of true variance of dispersal per generation. The latter then lies between $0.489 \mathrm{~m}^{2}(100$ days, site 6 , juveniles) and $6.404 \mathrm{~m}^{2}(4 \times 100$ days, site 2 , adults). These values, combined with the range of estimates of breeding adult density (39 to $202 \mathrm{~m}^{-2}$, give the neighbourhood number $(N)$ as between 240 and 16,257 (table 3):

TABLE 3

Estimates of range of $\mathrm{N}$, with $0.489<\sigma^{2}<6.404 \mathrm{~m}^{2}$

\begin{tabular}{ccccccc}
\hline Year & Site 1 & Site 2 & Site 3 & Site 4 & Site 5 & Site 6 \\
\hline 1977 & $910-11911$ & $1106-14486$ & $1241-16257$ & $535-7002$ & $320-4185$ & $615-8048$ \\
1978 & $565-7404$ & $774-10141$ & $676-8853$ & $615-8048$ & $602-7887$ & $694-9094$ \\
1979 & $350-4587$ & $578-7565$ & $701-9175$ & $424-5553$ & $442-5795$ & $1112-14567$ \\
1980 & $338-4426$ & - & $473-6197$ & $541-7082$ & $529-6921$ & - \\
1981 & $240-3139$ & $1204-15774$ & $258-3380$ & $811-10623$ & $246-3219$ & $953-12474$ \\
\hline
\end{tabular}

The effective neighbourhood number $\left(N_{e}\right)$ may depart from $N$ under certain conditions (Murray, 1964; Wright, 1969; Greenwood, 1974). The effects on this study are now dealt with in turn.

(i) Sex-ratio not unity. The term sex-ratio is redundant in a hermaphrodite species such as $T$. pisana, if one assumes that all individuals behave as males and females to the same extent.

(ii) Non-random fertilisation. In an obligately outbreeding hermaphrodite, fertilisation is not completely at random since self-fertilisation is precluded. In this case $N_{e}$ will differ, but only slightly, from $N$ :

$$
N_{e} \simeq N+0.5 \text { (Wright, 1969, p. 212). }
$$

Clearly this is of no importance in the present study.

Non-random fertilisation could also be caused by assortative mating. This has not been investigated in T. pisana, but neither Lamotte (1951) nor Wolda (1963) could find any evidence for it in Cepaea nemoralis in terms of either shell colour variation or shell size, these being the only characters investigated. It may occur, if at all, only to a very small extent, causing $N_{e}$ to differ from $N$ by only a few percent (Greenwood, 1974).

(iii) Non-random dispersal. Dispersal was probably not random, since the release area was not absolutely uniform and some micro-habitat selection probably took place. However, Wright (1951) remarked that $N_{e}$ was determined "largely irrespective of the form of the distribution curve" (of dispersal), and later (Wright, 1969) showed it to vary little with changing kurtosis (at least in a two-dimensional habitat). Non-random dispersal will therefore not alter greatly the present estimate of $N_{e}$.

(iv) Fluctuating population size. When density is fluctuating, the effective number is given by the harmonic mean of the number in successive generations, enhancing the importance of the smaller values (Wright, 1938, 1940; Crow and Morton, 1955). Implicit in this is the assumption that the fluctuations occur around a constant mean (Wright, 1969, p. 214), and indeed there was no obvious indication of an overall long-term trend in the Tenby 
colony (Cowie, 1982). The reduction of this effect, because of multiple mating and sperm storage (Murray, 1964) has been ignored in the present study, since although not negligible, it will be of less importance in the approximately semelparous T.pisana (Cowie, 1984b) than in the iteroparous $C$. nemoralis discussed by Murray (1964). It will increase the estimate of $N_{e}$, and it is the minimum estimate which is important in elucidating any significance of genetic drift. T. pisana is probably not absolutely biennial at Tenby; some individuals may reach maturity in one year, others requiring three (Cowie, $1980 \mathrm{~b}, 1984 \mathrm{~b}$ ). The adult populations of two consecutive years are thus not entirely separate. However, it seems a reasonable approximation to take the harmonic means of the estimates for 1977,1979 and 1981, and of the estimates for 1978 and 1980. This has been done for each site separately, and ranges obtained by taking the means of the lower estimates and the means of the higher estimates of $N$ for each year (table 3 ). The values obtained $(N)$ are given in table 4 .

TABLE 4

Harmonic means (N) of estimates of $\mathrm{N}$

\begin{tabular}{ccccccc}
\hline Years & Site 1 & Site 2 & Site 3 & Site 4 & Site 5 & Site 6 \\
\hline $1977,79,81$ & $369-4825$ & $866-11337$ & $491-6433$ & $549-7194$ & $317-4154$ & $839-10986$ \\
1978,80 & $423-5540$ & $774-10141$ & $557-7291$ & $576-7534$ & $563-7372$ & $694-9094$ \\
\hline
\end{tabular}

(v) Non-random variation in family size. The family size is the number of individuals reaching reproductive maturity contributed to by each adult. In a population of cross-fertilising hermaphrodites (equivalent to a population of dioecious organisms-Wright, 1969) the mean family size will be 2 if population size is constant; and if the contribution from each parent varies randomly (according to a Poisson distribution-Falconer, 1981), the variance will also be 2 . If it is not, this may affect $N_{e}$ considerably, since

$$
N_{e} \simeq \frac{4 N}{2+V_{f}} \quad \text { (after Wright, 1969) }
$$

in which $V_{f}$ is the variance in family size. Direct information on $V_{f}$ cannot easily be obtained from natural populations, but Crow and Morton (1955) have derived formulae relating it to the initial production of offspring. They produced two models, one based on random mortality of offspring between birth and maturity, and one based on mortality in family units. Greenwood (1974) combined these two models by introducing a term $U$, denoting the proportion of the juvenile mortality occurring in family units, assuming a constant population size. He gave his formula as:

$$
V_{f}=2+4(V / M+(M-2) U-2) /(M(1-U)+2 U) .
$$

Correctly it should read (Greenwood, personal communication):

$$
V_{f}=2+4(V / M+(M-2) U-1) /(M(1-U)+2 U)
$$

in which $M$ and $V$ are the mean and variance of the number of offspring produced. In a laboratory study of $T$. pisana, the minimum estimate of 
mean lifetime egg production per pair (and therefore the number contributed to by each adult) was 368 and the variance 173,056 (Cowie, in press $b$ ). Greenwood (1974) argued that for $C$. nemoralis $U$ would be about $0 \cdot 3$. The value of $N_{e}$ is robust to differences in $U$, particularly when $U$ is low, so $U=0.3$ will be used here. Combining it with values of $M$ (368) and $V(173,056)$, Greenwood's equation gives us $V_{f}=8 \cdot 98$. This yields a range of $N_{e}$ from 115 (site 5 , lowest estimate of $\tilde{N}=317$ ) to 4130 (site 2, highest estimate of $\tilde{N}=11,337$ ).

\section{Discussion}

\section{(i) Density}

The values of 39 to $202 \mathrm{~m}^{-2}$ (adults) and 13 to $436 \mathrm{~m}^{-2}$ (juveniles) are within the very broad range of estimates of previous authors. Hickson (1972) estimated total population density as between 6 and $33 \mathrm{~m}^{-2}$, and Johnson (1981) gave values of 2.6 to $4 \cdot 0 \mathrm{~m}^{-2}$ for adults. Both these studies were of duneland areas, probably more sparsely vegetated than the Tenby sites. Lazaridou-Dimitriadou and Daguzan (1981) gave values of 1 to $9 \mathrm{~m}^{-2}$ in duneland, and 110 to $1200 \mathrm{~m}^{-2}$ in a more densely vegetated habitat; these figures are extremes for a whole year and include both adults and juveniles; the high figure of $1200 \mathrm{~m}^{-2}$ probably occurred during the breeding season. Basinger (1927) estimated well over $200 \mathrm{~m}^{-2}$ (21 per square foot) and included all age classes.

Certainly, T. pisana is well known (e.g., Taylor, 1912: Germain, 1929, 1930) for its ability to reach densities much higher than many other species of terrestrial snail (e.g., Helix aspersa-Potts, 1975; Crook, 1980; Cepaea nemoralis-estimates of various authors summarised by Williamson, Cameron and Carter, 1977; Aegopinella and Nesovitrea-Mordan, 1977; Caracolus carocollus-Heatwole and Heatwole, 1978). Higher densities, approaching those attained by $T$. pisana, have been reported for species of Cerion by Woodruff (1978), for Candidula intersecta (= Helicella caperata) by Baker (1968), and for Cernuella (= Helicella) virgata by Pomeroy (1969), although in both the latter cases the highest densities were only attained immediately after breeding.

Aggregation has previously been reported both for $T$. pisana (Lazaridou-Dimitriadou and Daguzan, 1981) and for other species of snail (e.g., Baker, 1968; Pomeroy, 1969; Crook, 1980). It can result in two ways: selection of preferred areas within the habitat, and/or some form of interaction between individuals (e.g., Hamilton, 1971). The latter may be important on a very small scale; $T$. pisana forms clusters on the stems it uses as resting sites, perhaps benefitting from the shade of other snails (McQuaid, Branch and Frost, 1979; Cowie, 1982). The aggregation seen in this study is almost certainly due to selection of particular plants for resting positions (and perhaps for food), and adults and juveniles show different preferences (Cowie, 1982).

\section{(ii) Dispersal}

Although Cowie $(1980 a)$, in a study of dispersal in two other species of land snail, did not detect any effect of overcrowding at the release point 
on subsequent dispersal, it is possible that this and the other factors mentioned earlier may mean that the estimates of dispersal presented here for T. pisana are not very accurate. However, they are of a similar magnitude to those of Hickson (1972) for T. pisana in South Africa $\left(0 \cdot 159-1.052 \mathrm{~m}^{2}\right)$, but far less than those of Greenwood (1974) for Cepaea nemoralis (30$100 \mathrm{~m}^{2}$ ) and of Crook (1980) for Helix aspersa $\left(17-45 \mathrm{~m}^{2}\right)$. These data imply that $T$. pisana is much more sedentary than these other species, although Johnson (1981), working on $T$. pisana in Australia, showed that while most of his snails remained within $5 \mathrm{~m}$ of his release points over their active season, a small number travelled much further. Dürr (1946) described a similar experiment to that reported here and concluded that $T$. pisana showed a "reluctance to migrate"; and Humphreys (1976) provided some further evidence of its sedentary nature. Other studies of dispersal in snails (Paul, 1978; Cowie, 1980a) were for much shorter periods.

\section{(iii) Neighbourhood size}

At all stages of this study, the need for a minimum estimate of neighbourhood size has been borne in mind (cf. Begon, Krimbas and Loukas, 1980). It seems unlikely that dispersal variance per generation would be lower than the minimum value used; and the minimum estimate of density seems appropriate for the Tenby colony. However, the assumption of constant population size over the long term, although not contradicted by the density estimates (tables 1 and 2), may not be valid. $T$. pisana is under considerable pressure at Tenby from urban development and tourism (Cowie, 1982) and populations may be diminishing. This would lower the estimate of $N_{e}$ by an amount depending on whether it was the inbreeding effective number or the variance effective number (Wright. 1969, p. 211) which was being considered. Wright (1969, p. 219) gave these as:

$$
\begin{aligned}
\text { Inbreeding } N_{e} & =\frac{N \bar{k}}{\left(\bar{k}-1+V_{f} / \bar{k}\right)} \\
\text { Variance } N_{e} & =\frac{2 N}{\left(1+V_{f} / \bar{k}\right)}
\end{aligned}
$$

in which $\bar{k}$ is the mean family size. When population size is constant, as assumed earlier (i.e., $\bar{k}=2$ ), these are equal. If it were decreasing by 25 per cent per generation $(\bar{k}=1 \cdot 5)$, this would lower the minimum estimate of the inbreeding effective number to 73 , and of the variance effective number to 91 (for $N=137, V_{f}=8.98$ ). The estimate would be further reduced if the assumptions of random fertilisation and random dispersal were not true. Furthermore, if $V_{f}$ were larger in the field than in the laboratory, because of greater differentials in fecundity and survival, the estimate of neighbourhood size would again be lowered.

Although it is not possible to deduce much about the importance of drift on the basis of an estimate of neighbourhood size without knowledge of selection coefficients, the minimum estimate obtained in this study (115) is in the region in which it is difficult to discount drift as a potential force (Wright, 1943; Begon, 1977). The present upper estimate (4130) is, however, effectively infinite as far as stochastic processes are concerned. 
Elsewhere, where populations of $T$. pisana are more sparse, more isolated, and in which bottlenecks may occasionally take place, drift could be of considerably more consequence than it appears to be in the Tenby colony.

Greenwood (1974) estimated neighbourhood size $(N)$ for Cepaea nemoralis as between 380 and 14,000 with the effective size as about half this. He later corrected these values (Greenwood, 1976) such that $N$ lay 180 and 12,000; and therefore $N_{e}$ would lie between 95 and 6000 , figures very similar to those estimated here for $T$. pisana. This similarity does obscure, however, the differences between these two species in dispersal and population density, T. pisana appearing more sedentary, but often existing at much higher densities than $C$. nemoralis. Selander and Kaufman (1975), working on Helix aspersa, considered the snails in their study area to be in small, discrete colonies, and estimated effective population size (not neighbourhood size) as about 15 , on the basis of heterogeneity between colonies in allozyme frequencies. They considered this heterogeneity to be in part due to founder effects. However, their study did not measure dispersal, although they suggested that human disturbance could introduce some mixing of the colonies, which they proposed would result in a "quasipanmictic" unit of effective size about 400 , a figure perhaps more appropriately comparable with the estimates of neighbourhood size for $T$. pisana and $C$. nemoralis. Crook (1980) also estimated neighbourhood size in two colonies of $H$. aspersa, as 512 and 36 , which he reduced to effective sizes of 215 and 15 respectively. His results emphasize the fact that estimates of neighbourhood size such as those discussed here only refer to the particular colonies studied, and generalisations from them to characteristic values for a species must be cautious.

These values of neighbourhood size, except the lower ones for $H$. aspersa, are of a similar order to those available for many other organisms, but rather higher than those for some mammals and plants (see e.g., Wright, 1978; Begon, Krimbas and Loukas, 1980, for references). They are not strictly comparable with the values derived from long-term chromosomal evolution by Lande (1979) of 30-200 in mammals, 40-300 in lower vertebrates, and 200-800 in dipterans like Drosophila, since these are effective population sizes based on assumption of evolution in discrete panmictic units.

Acknowledgments. I thank Professor A. J. Cain for his supervision of this study, and Dr N. H. Barton for much clarifying discussion and for critically reading a draft of this paper. I also thank those in the Zoology Department at Liverpool and the Genetics Department in London who gave me the opportunity to carry out this work.

\section{REFERENCES}

BAKER, R, E. 1968. The ecology of the wrinkeld snail, Helicella caperata Mont. on the Braunton Burrows sand dune system. Proc. Malac. Soc. Lond., 38, 41-54.

BASINGER, A. J. 1927. The eradication campaign against the white snail (Helix pisana) at La Jolla, California. Calif. Dept. Agric. Bull., 16, 51-77.

BEGON, M. 1977. The effective population size of a natural Drosophila subobscura population. Heredity, 38, 13-18.

BEGON, M., KRIMBAS, C. B. AND LOUKAS, M. 1980. The genetics of Drosophila subobscura populations. XV. Effective size of a natural population estimated by three independent methods. Heredity, 45, 335-350. 
COWIE, R. H. $1980 a$. Observations on the dispersal of two species of British land snail, $J$. Conch., Lond., 30, 201-208.

COWIE, R, H. 1980b. Precocious breeding of Theba pisana (Müller) (Pulmonata: Helicidae). J. Conch., Lond., 30, 238.

COWIE, R. H. 1982. Studies on the ecology and ecogenetics of the helicid land snail Theba pisana (Müller). Ph.D. Thesis, University of Liverpool.

COWIE, R. H. 1984a. Ecogenetics of Theba pisana (Pulmonata: Helicidae) at the northern edge of its range. Malacologia, 25, 361-380.

COWIE, R. H. 1984b. The life-cycle and productivity of the land snail Theba pisana (Mollusca: Helicidae). J. Anim. Ecol., 53, 211-325.

CROOK, S. J. 1980. Studies on the ecological genetics of Helix aspersa (Müller). Ph.D. Thesis, University of Dundee.

CROW, J. F. AND MORTON, N. E. 1955. Measurement of gene frequency drift in small populations. Evolution, 9, 202-214.

DOBZHANSKY, TH. AND WRIGHT, S. 1943. Genetics of natural populations. X. Dispersion rates in Drosophila pseudoobscura. Genetics, 28, 304-340.

DURR, H. J. R. 1946. A contribution to the morphology and bionomics of Theba pisana (Müller) (Gastropoda: Helicidae). Sci. Bull. Dep. Agric. S. Afr., Number 257, 34 pp.

FALCONER. D. S. 1981. Introduction to Quantitative Genetics, 2nd Edn., Longman, London. GERMAIN, L. 1929. Les Helicidae de la Faune française. Arch. mus, hist. nat. Lyon, 13, 1-484. GERMAIN, L. 1930. Mollusques terrestres et fluviatiles, pt. 1. Faune Fr., 21, 1-477.

GREENWOOD, J. J. D. 1974. Effective population numbers in the snail Cepaea nemoralis. Evolution, 28, 513-526.

GREENWOOD, J. J. D. 1976. Effective population number in Cepaea: a modification. Evolution, $30,186$.

HAMILTON, W. D. 1971. Geometry for the selfish herd. J. Theoret. Biol., 31, 295-311.

HEATWOLE, H. AND HEATWOLE, A. 1978. Ecology of the Puerto Rican camaenid land snails. Malacologia, 17, 241-316.

HICKSON, T. G. L. 1972. A possible case of genetic drift in colonies of the land snail Theba pisana. Heredity, 29, 177-190.

HUMPHREYS, J. 1976. Field observations on Theba pisana (Müller) (Gastropoda: Helicidae) at St. Ives, Cornwall. J. Conch., Lond., 29, 93-106.

JOHNSON, M. S. 1981. Effects of migration and habitat choice on shell banding frequencies in Theba pisana at a habitat boundary. Heredity, 47, 121-133.

KERNEY, M. P. 1976. Atlas of the Non-Marine Mollusca of the British Isles, Institute of Terrestrial Ecology, Cambridge.

KERSTER, H. W. 1964. Neighbourhood size in the rusty lizard, Sceloporus olivaceus. Evolution, $18,445-457$.

LAMOTTE. M. 1951. Recherches sur la structure génétique des populations naturelles de Cepaea nemoralis (L.). Bull. Biol. Fr. Belg. suppl., 35, 1-238.

LANDE, R. 1979. Effective deme sizes during long-term evolution, estimated from rates of chromosomal rearrangement. Evolution, 33, 234-251.

LAZARIDOU-DIMITRIADOU, M. AND DAGUZAN, J. 1981. Etude de l'effet du "groupement" des individus chez Theba pisana (Mollusque Gastéropode Pulmoné Stylommatrophore). Malacologia, 20, 195-204.

MCQUAID, C. D., BRANCH, G. M. AND FROST, P, G. H. 1981. Aestivation behaviour and thermal relations of the pulmonate Theba pisana in a semi-arid environment. J. Therm. Biol., 4, 47-55.

MORDAN, P. B. 1977. Factors affecting the distribution and abundance of Aegopinella and Nesovitrea (Pulmonata: Zonitidae) at Monks Wood National Nature Reserve, Huntingdonshire. Biol. J. Linn. Soc., 9, 59-72.

MURRAY, J. 1964. Multiple mating and effective population size in Cepaea nemoralis. Evolution, 18, 283-291.

PAUL, C. R. C. 1978. The ecology of Mollusca in ancient woodland. II. Analysis of distribution and experiments in Hayley Wood, Cambridgeshire. J. Conch., Lond., 29, 281-294.

POMEROY, D. E. 1969. Some aspects of the ecology of the land snail Helicella virgata in South Australia. Austr. J. Zool, 17, 495-514.

POTTS, D. C. 1975. Persistence and extinction of local populations of the garden snail Helix aspersa in unfavourable environments. Oecologia (Berl.), 21, 313-334.

SELANDER, R. K. AND KAUFMAN, D. W. 1975. Genetic structure of populations of the brown snail (Helix aspersa). I. Microgeographic variation. Evolution, 29, 385-401.

SOUTHWOOD, T. R. E. 1978. Ecological Methods 2nd Edn. Chapman and Hall, London. 
TAYLOR, J. W. 1912. Monograph of the Land and Freshwater Mollusca of the British Isles, Vol. 3, Part 19, Taylor Brothers, Leeds.

WILliamson, P., CAMERON, R. A. D. AND CARTER, M. A. 1977. Population dynamics of the land snail Cepaea nemoralis L.: A six-year study. J. Anim. Ecol, 46, 181-194.

WOLDA, H. 1963. Natural populations of the polymorphic landsnail Cepaea nemoralis (L.). Factors affecting their size and their genetic constitution. Arch. Néerl. Zool., 15, 381-471. WOODRUFF, D. S. 1978. Evolution and adaptive radiation of Cerion: a remarkably diverse group of West Indian land snails. Malacologia, 17, 223-239.

WRIGHT, S. 1938. Size of population and breeding structure in relation to evolution. Science, $87,430-431$.

WRIGHT, s. 1940. Breeding structure of populations in relation to speciation. Am. Nat., 74, 232-248.

WRIGHT, S. 1943. Isolation by distance. Genetics, 28, 114-138.

WRIGHT, S. 1951. The genetical structure of populations. Ann. Eugen., 15, 323-254.

WRIGHT, S. 1969. Evolution and genetics of populations. Vol. II. The theory of gene frequencies, Chicago University Press, Chicago.

WRIGHT, S. 1978. Evolution and genetics of populations. Vol. IV. Variation within and among natural populations, Chicago University Press, Chicago. 